\title{
Laminoplasty with selective fusion at unstable segment versus laminectomy with fusion for multilevel cervical myelopathy: a case-control study
}

\author{
Lin Du ${ }^{1,2}$, Yanzheng Gao', Changqing Zhao ${ }^{2}$, Tangjun Zhou², Haijun Tian², Kai Zhang² and Jie Zhao ${ }^{2 *}$
}

\begin{abstract}
Background: Segmental cervical instability is a risk factor for the progression of osteophytic bone spurs and development of myelopathy, and is treated as a relative contraindication of cervical laminoplasty. The aim of this study was to compare laminoplasty with selective fixation (LPSF) versus laminectomy with fusion (LCF) in patients with multilevel cervical myelopathy accompanied by segmental instability.

Methods: A case-control study was conducted by reviewing data from 63 patients who underwent LPSF $(n=30)$ or LCF $(n=33)$. Cervical alignment, range of motion (ROM), neurologic status and axial symptom severity pre-operation, 3days after operation, and at the final follow-up (minimum 24 months) were measured and compared between groups.

Results: Postoperation, patients in the LPSF group lost $31.1 \pm 17.3 \%$ of cervical lordosis and $43.2 \pm 10.9 \%$ cervical ROM while patients in the LCF group lost $5.7 \pm 8.2 \%$ and $67.9 \pm 15.5 \%$, respectively. Both LPSF and LCF groups significantly improved neurologic status and axial symptom severity at the final follow-up with similar between-group results $(P>$ 0.05). Blood loss, operation time, hospital stay, and medical cost in the LPSF group were significantly less than in the LCF $\operatorname{group}(P<0.05)$.

Conclusions: In 2 years of clinical observation, LPSF was effective in maintaining the stability of the cervical spine with less sacrifice of mobility and surgical trauma for multilevel myelopathy with segmental instability compared to LCF.
\end{abstract}

Keywords: Myelopathy, Segmental instability, Laminectomy and fusion, Laminoplasty, Selective fusion

\section{Background}

Multilevel degenerative changes and ossification of the posterior longitudinal ligament (OPLL) in the cervical spine leading to myelopathy has been studied extensively. Posterior decompression, including laminoplasty and laminectomy with fusion (LCF), are common procedures for multilevel spinal cord decompression.

\footnotetext{
* Correspondence: sh9hzhaojie@163.com

${ }^{2}$ Shanghai Key Laboratory of Orthopedic Implants, Department of Orthopedics, Shanghai Ninth People's Hospital, Shanghai Jiao Tong University School of Medicine, 639 Zhizaoju Road, 200011 Shanghai, People's Republic of China

Full list of author information is available at the end of the article
}

Multilevel myelopathy often coexists with segmental dynamic instability, a degenerative change frequently seen in the elderly population. Segmental dynamic instability is a risk factor for the progression of osteophytic bone spurs and development of myelopathy $[1,2]$. Laminoplasty is not an appropriate choice for this type of patient, because it can aggravate pre-existing segmental spinal instability which predisposes a patient to loss of cervical lordosis that may progress to kyphosis [3, 4]. Cervical kyphosis prevents indirect decompression and is associated with delayed neurologic deterioration and axial neck pain [5]. Therefore, laminectomy and fusion

(c) The Author(s). 2021 Open Access This article is licensed under a Creative Commons Attribution 4.0 International License, which permits use, sharing, adaptation, distribution and reproduction in any medium or format, as long as you give appropriate credit to the original author(s) and the source, provide a link to the Creative Commons licence, and indicate if changes were made. The images or other third party material in this article are included in the article's Creative Commons licence, unless indicated otherwise in a credit line to the material. If material is not included in the article's Creative Commons licence and your intended use is not permitted by statutory regulation or exceeds the permitted use, you will need to obtain permission directly from the copyright holder. To view a copy of this licence, visit http://creativecommons.org/licenses/by/4.0/. The Creative Commons Public Domain Dedication waiver (http://creativecommons.org/publicdomain/zero/1.0/) applies to the data made available in this article, unless otherwise stated in a credit line to the data. 
are commonly recommended for this group of patients. Despite posterior instrumentation to stabilize unstable segments and prevent post-laminectomy kyphosis, it has been recognized that without the protection of the lamina, adhesion formation may occur and lead to neurologic deterioration [6]. In addition, decrease in cervical range of motion (ROM) and higher incidence rate of $\mathrm{C} 5$ motor palsies [7] have been reported after LCF procedures.

Laminoplasty with fixation at the unstable segments was first reported by $\mathrm{Yu}$ et al. for the treatment of OPLL associated with segmental instability [8,9]. Different from classic laminectomy with fusion and laminoplasty, this technique only fixes unstable segments after laminoplasty, while retaining the mobility of stable segments. Therefore, we call it laminoplasty with selective fixation at unstable segments (LPSF). This new technique has the potential to provide a stable environment for spinal cord recovery and prevents the progression of kyphosis and ossification, but also preserves the cervical ROM. However, there is a paucity of evidence-based comparisons between this promising new technology and standard LCF surgery. The current study addresses this gap, comparing outcomes between LPSF and LCF surgery for patients with identical operative indications in the hands of a single surgeon. The purpose of the present retrospective cohort study was to compare radiological and clinical outcomes of LPSF with LCF in the treatment of patients with multilevel cervical myelopathy accompanying segmental instability. We hypothesized that fixation at the unstable segments would not only maintain cervical sagittal alignment, but also preserve cervical motion, and then result in superior clinical outcomes than LCF surgery.

\section{Methods}

\section{Patient selection}

We reviewed medical records and radiological data of 255 patients who were diagnosed with cervical myelopathy and underwent posterior decompression surgery at Shanghai Ninth People's Hospital between March 2010 and March 2015 (Fig. 1). We follow up patients in the outpatient clinic, and all patients take X-rays at each follow-up. The minimum follow-up time is 2 years.

Only patients with segmental dynamic instability were included in the study, which was confirmed by flexionextension lateral radiography. The radiological criterion was defined as more than $3.5 \mathrm{~mm}$ horizontal displacement of one vertebra in relation to an adjacent vertebra or more than $11^{\circ}$ change of segmental lordotic angle on pre-operation cervical dynamic lateral view radiography according to White and Panjabi standards [10].

Patients with cervical kyphosis alignment, a previous history of cervical spine surgery, decompression extended to
$\mathrm{C} 2$ or T1, or loss to follow-up within 2 years after surgery were excluded from the study. The final study sample consisted of 63 patients with 30 patients in the LPSF group (Fig. 2a and b) and 33 patients in the LCF group (Fig. 2c and d). The LCF group was set as control group, because laminectomy and fusion are commonly recommended for multilevel myelopathy coexist with segmental instability. Laminoplasty was not set as control group, because Laminoplasty is not an appropriate choice for this type of patient. All patients included in the study showed symptoms such hand clumsiness, gait instability, loss of coordination, as well as spinal cord compression confirmed by magnetic resonance imaging (MRI) and computed tomography (CT) that could explain their symptoms.

\section{Surgical technique}

For all patients, posterior decompression started at C3 and terminated at $\mathrm{C} 6$ or $\mathrm{C} 7$ and surgery was performed by the senior author (J.Z.). After induction of general anaesthesia, the patient was positioned prone in a prefabricated plaster cast. The unstable segment was confirmed by radiological findings. If LPSF was planned, the open side was placed on the side with the greater degree of symptoms. A laminoplasty plate was employed to support the lamina in a decompression position (Centerpiece, Medtronic Sofamor Danek, USA). Unilateral pedicle screw fixations were performed at the unstable segments. For these, the pedicle screws were inserted at the pedicle opposite to the side of dominance of the vertebral artery, regardless of whether the side was the open or hinge side. Autologous bone grafts were placed over the unstable segments on the hinge side. If LCF was scheduled, en bloc resection of the laminae and instrumentation with pedicle screw or lateral mass screw on the decompression segments were performed. For all patients, poly-axial screws combination with $3.5 \mathrm{~mm}$ titanium rods were used for posterior instrumentation (Vertex, Medtronic Sofamor Danek, USA). Postoperatively, all patients were taught to wear a Philadelphia collar for comfort and were encouraged to perform early neck muscle exercises.

\section{Radiographic evaluation}

We evaluated the cervical alignment in upright standard lateral view radiographs obtained preoperatively, 3-days after operation, and at the final follow-up. Cervical sagittal alignment was assessed by the C2-7 Cobb angle. The $\mathrm{C} 2-\mathrm{C} 7 \mathrm{Cobb}$ angle was defined as the angle between the line parallel to the inferior endplate of $\mathrm{C} 2$ and $\mathrm{C} 7$ (Fig. 3a). Straight alignment was defined as fewer than $4^{\circ}$ of either the kyphotic or lordotic angulations. Postoperative loss of cervical lordosis (LCL) was calculated with the following formula: LCL $(\%)=(3-$ day $\mathrm{C} 2-7 \mathrm{Cobb}$ angle - final C2-7 Cobb angle) /3-day C2-7 Cobb angle $\times 100 \%$ [11]. 


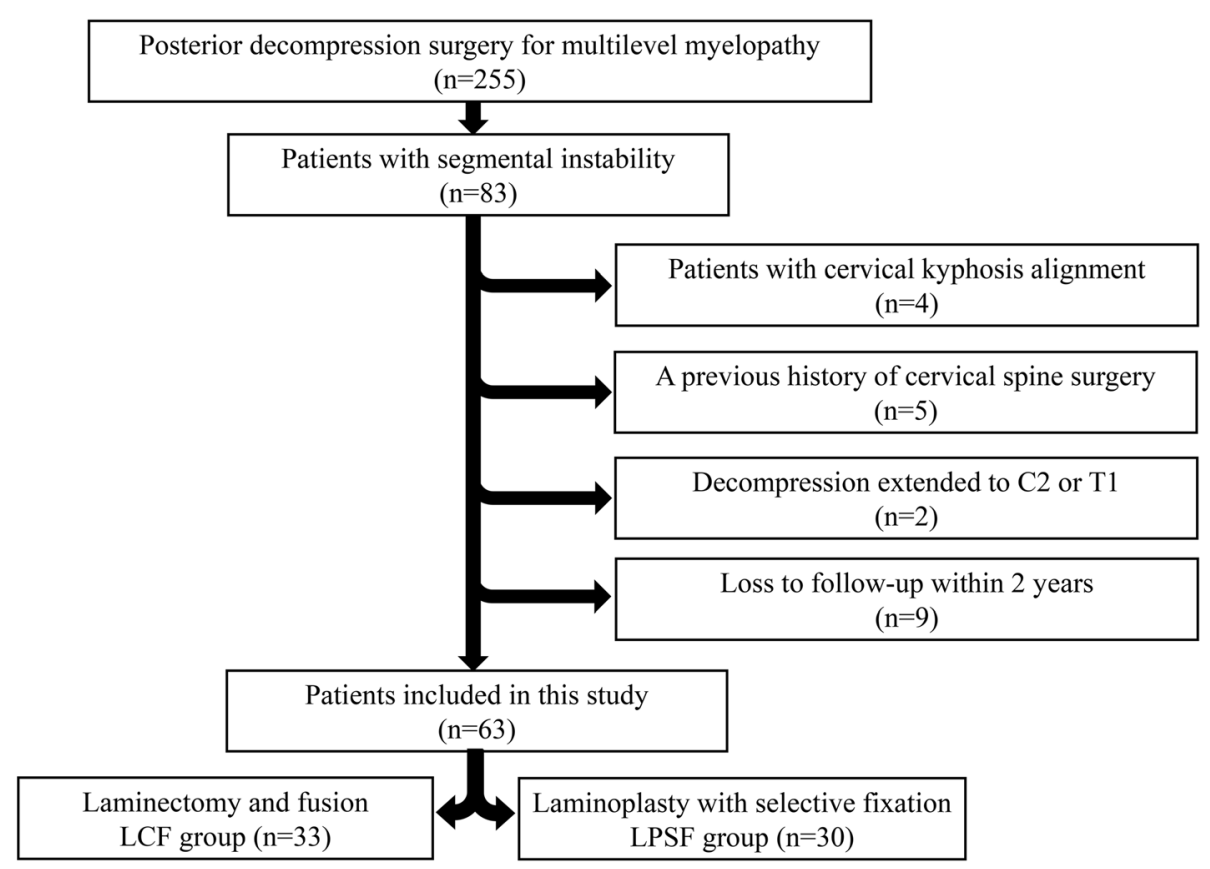

Fig. 1 The flowchart of patient inclusion and exclusion

Dynamic lateral views of the cervical spine taken before surgery and at the final follow-up were used to evaluate cervical $\mathrm{ROM}$ changes. We defined the cervical $\mathrm{ROM}$ as the sum of $\mathrm{C} 2-7 \mathrm{Cobb}$ angle measured on flexion-extension lateral radiographs (Fig. 3b and c) [12]. Loss of ROM (\%) was calculated as (preoperative ROM - postoperative ROM) / preoperative $\mathrm{ROM} \times 100 \%$. Measurements are performed using tools provided by the SYNAPSE Picture Archiving and Communication Systems. To evaluate and minimize interrater and intrarater difference, all radiologic images were evaluated 3 times by 2 of the authors ( $\mathrm{LD}$ and $\mathrm{CZ}$ ) independently and the mean value was used for analysis.

\section{Clinical evaluation}

Clinical evaluation was made preoperatively and at the final follow-up. Neurological status was evaluated using the Japanese Orthopaedic Association (JOA) disability scale and axial symptom severity was quantified by the Visual Analogue Scale (VAS) and Neck Disability Index (NDI) [13]. The neurological recovery rate was calculated based on the following formula: recovery rate= (postoperative JOA score - preoperative JOA score) / (17 - preoperative JOA score) $\times 100 \%$ [14]. Data on surgical parameters including duration, bleeding amount, length of hospital stay, and medical costs were also collected.
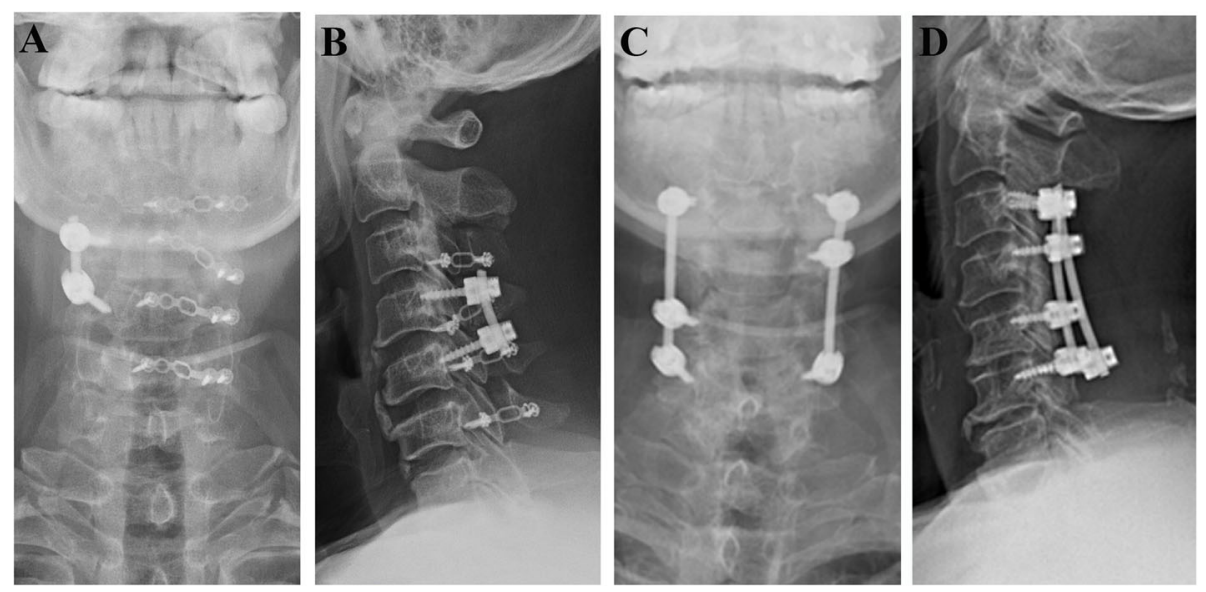

Fig. 2 Postoperative cervical radiography of patients treated with laminoplasty and fixation at the unstable segment (a and $\mathbf{b})$ and laminectomy and fusion (c and $\mathbf{d}$ ) 

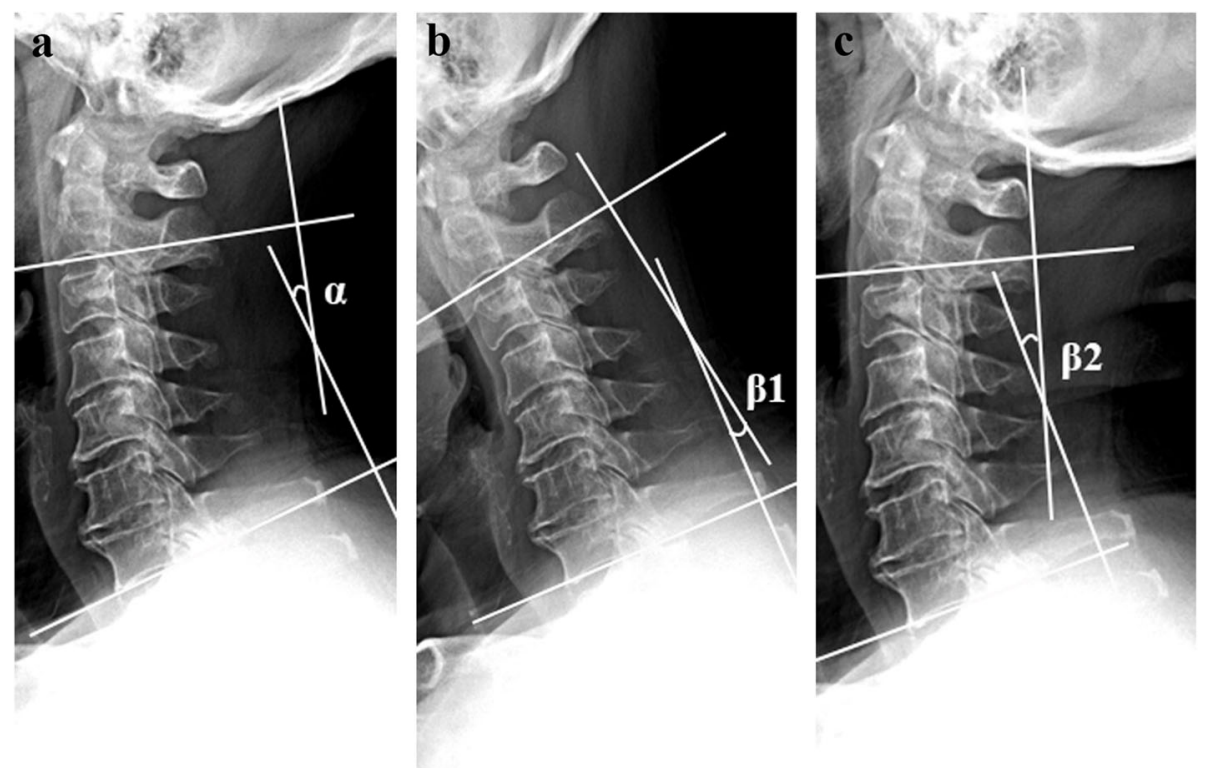

Fig. 3 The C2-C7 Cobb (a) angle was defined as the angle between the line parallel to the inferior endplate of C2 and C7 (a). The cervical range of motion (ROM) was defined as the sum of C2-7 Cobb angles measured on flexion-extension lateral radiographs (b and $\mathbf{c}) \cdot R O M=\beta 1+\beta 2$

Postoperative complications, including wound infection, instrumentation failure, cerebrospinal fluid (CSF) leak and nerve root palsy were recorded in detail.

\section{Statistical analysis}

All continuous variables are reported as the mean \pm standard deviation (SD) and categorical variables as frequencies and percentages. The Fisher's exact test or chisquare test was used for comparison of categorical variables. For comparison of continuous variables between groups, we used independent sample $t$ test if the assumptions of equal variance and the Gaussian distribution were met. Otherwise, a nonparametric MannWhitney test was used. To determine statistical significance of changes between preoperative and follow-up parameters in each group, we used paired $t$ tests. Our missing data analysis procedures used missing at random (MAR) assumptions. We averaged estimates of the variables to give a single mean estimate and adjusted standard errors according to Rubin's rules. Statistical analyses were performed using SPSS version 22.0 for Windows (SPSS, Inc., Chicago, IL, USA). p values $<0.05$ based on a 2 -sided hypothesis test were considered significant. The study power $(1-\beta)$ for complications comparison was calculated with PASS 15 software (NCSS, LLC, Kaysville, Utah, USA).

\section{Results}

\section{Baseline results}

The general characteristics of patients are shown in Table 1. Of the 63 patients included in this study, the mean follow-up period was $29.0 \pm 3.0$ months in the
LPSF group and $30.1 \pm 3.7$ in the LCF group. All of the 63 patients included in this study completed 2-year follow-up. No significant difference was detected among the groups in baseline demographic including sex $(p=$ $0.597)$, age $(p=0.073)$, symptomatic duration $(p=0.085)$, follow-up period $(p=0.240)$, BMI $(p=0.189)$, Diabetes mellitus $(p=0.614)$, smoking $(p=0.182)$, and diagnosis $(p=0.556)($ Table 1$)$.

\section{Radiological analysis}

There were 25 one-segment and 5 two-segment fixation (1.2 segments fixed in average )in the LPSF group; and there were 10 three-segment and 23 four-segment fixation (3.7 segments fixed in average ) in the LCF group. The mean pre-operation $\mathrm{C} 2-7 \mathrm{Cobb}$ angle was $17.5 \pm$ $7.7^{\circ}$ in the LCF group and $17.4 \pm 8.0^{\circ}$ in the LPSF group. No patients with kyphosis cervical alignment were included in either group and the difference was not statically significant between the groups. After operation, both groups showed a slight increase in $\mathrm{C} 2-7 \mathrm{Cobb}$ angle. At the final follow-up the cervical alignment decreased by $5.7 \%$ to $18.4 \pm 6.9^{\circ}$ in the LCF group and by $31.1 \%$ to $13.4 \pm 7.7^{\circ}$ in the LPSF group. The change in sagittal alignment between the LCF and LPSF groups was statically different at the final follow-up $(\mathrm{P}<0.001)$ (Table 2).

Preoperatively, the cervical ROM of the LPSF and LCF was $32.7 \pm 8.8^{\circ}$ and $33.7 \pm 8.4^{\circ}$, respectively. At the final follow-up, both groups showed a significant reduction in ROM, however the magnitude of reduction was much 
Table 1 Baseline patient demographics

\begin{tabular}{llll}
\hline Variables & Group LPSF $(\boldsymbol{n}=\mathbf{3 0})$ & Group LCF $(\boldsymbol{n}=\mathbf{3 3})$ & $\boldsymbol{p}$ value \\
\hline Gender & & & 0.597 \\
$\quad$ Male (\%) & $21(70.0)$ & $20(60.6)$ & $13(39.4)$ \\
Female (\%) & $9(30.0)$ & $64.6 \pm 7.4$ & 0.073 \\
Age (years) & $61.1 \pm 7.7$ & $24.5 \pm 3.9$ & 0.189 \\
BMI (kg/m $\left.{ }^{2}\right)$ & $23.2 \pm 4.2$ & $13(39.4)$ & 0.182 \\
Smoker (\%)) & $7(23.3)$ & $6(18.2)$ & 0.614 \\
Diabetes mellitus & $7(23.3)$ & $43.4 \pm 8.9$ & 0.085 \\
Symptomatic duration (months) & $39.1 \pm 10.9$ & $30.1 \pm 3.7$ & 0.240 \\
Follow-up period (months) & $29.0 \pm 3.0$ & & 0.556 \\
Diagnosis & & 24 & 9 \\
CSM & 19 & & \\
OPLL & 11 & & \\
\hline
\end{tabular}

LPSF laminoplasty and selective fixation at the unstable segment; LCF laminectomy and fusion; BMI body mass index; CSM cervical spondylotic myelopathy; OPLL ossification of the posterior longitudinal ligament

larger in the LCF group $67.9 \pm 15.5 \%$ than in the LPSF group $43.2 \pm 10.9 \%(p<0.001)$ (Table 2$)$.

\section{Clinical analysis}

There were no significant differences in preoperative self-reported clinical data between the 2 groups. Both groups (LPSF and LCF) showed significant improvement in their JOA, NDI and VAS scores postoperatively. The JOA score improved from $8.9 \pm 2.3$ (preoperative) to $14.1 \pm 2.5$ (postoperative) in the LPSF group and from $9.3 \pm 2.5$ (preoperative) to $14.5 \pm 2.0$ (postoperative) in the LCF group. The recovery rates of the JOA scores at the final follow-up was $66.8 \pm 25.7 \%$ in the LPSF group and $66.1 \pm 26.9 \%$ in the LCF group. No significant difference was detected in the final JOA score and JOA recovery rate between the 2 groups. Comparison of VAS and NDI score at the final follow-up showed that axial pain was not significantly different between the 2 groups (VAS: $p=0.722$, NDI: $p=0.432$ ) (Table 3$)$.
In the LCF compared with LPSF group, there were longer operating times, greater amount of blood loss, longer hospital stays, and higher medical costs, and the differences were statistically significant. There were 1 nerve root palsy in the LCF group and 8 in the LPSF group. Based on previous reports, nerve root palsy occurs in $5-16 \%$ of patients undergoing posterior decompression[15-17], the power with regard to nerve root palsy was calculated. However, with a sample size of 30 subjects in the LPSF group and 33 subjects in the LCF group, the current study has only $12.9 \%$ power to detect the difference of nerve root palsy occurrence between two groups. The incidence of superficial wound infection and CSF leakage were low in both groups. Spinal fusion was noted in $100 \%$ of patients at the last follow-up. No instrumentation failure or reoperation was reported in this group of patients (Table 3).

\section{Discussion}

The purpose of the present study was to compare radiological and clinical outcomes of LPSF with LCF in the

Table 2 Radiographic outcomes

\begin{tabular}{|c|c|c|c|}
\hline Variables & Group LPSF $(n=30)$ & Group LCF $(n=33)$ & $p$ value \\
\hline \multicolumn{4}{|l|}{ C2-7 Cobb angle } \\
\hline Preoperative $\left({ }^{\circ}\right)$ & $17.4 \pm 8.0$ & $17.5 \pm 7.7$ & 0.941 \\
\hline 3-day Postoperative $\left({ }^{\circ}\right)$ & $18.1 \pm 8.2$ & $19.3 \pm 6.0$ & 0.528 \\
\hline Final $\left({ }^{\circ}\right)$ & $13.4 \pm 7.7$ & $18.4 \pm 6.9$ & 0.013 \\
\hline loss of cervical lordosis (\%) & $31.1 \pm 17.3$ & $5.7 \pm 8.2$ & $<0.001$ \\
\hline \multicolumn{4}{|l|}{ Cervical ROM } \\
\hline Preoperative $\left({ }^{\circ}\right)$ & $32.7 \pm 8.8$ & $33.7 \pm 8.4$ & 0.647 \\
\hline Final $\left({ }^{\circ}\right)$ & $19.2 \pm 8.2$ & $10.1 \pm 3.7$ & $<0.001$ \\
\hline loss of ROM (\%) & $43.2 \pm 10.9$ & $67.9 \pm 15.5$ & $<0.001$ \\
\hline
\end{tabular}

LPSF laminoplasty and selective fixation at the unstable segment; LCF laminectomy and fusion; ROM range of motion 
Table 3 Clinical outcomes

\begin{tabular}{|c|c|c|c|}
\hline Variables & $\begin{array}{l}\text { Group LPSF } \\
(n=30)\end{array}$ & $\begin{array}{l}\text { Group LCF } \\
(n=33)\end{array}$ & $P$ value \\
\hline \multicolumn{4}{|l|}{ JOA score } \\
\hline Preoperative & $8.9 \pm 2.3$ & $9.3 \pm 2.5$ & 0.481 \\
\hline Final & $14.1 \pm 2.5$ & $14.5 \pm 2.0$ & 0.579 \\
\hline Recovery rate (\%) & $66.8 \pm 25.7$ & $66.1 \pm 26.9$ & 0.968 \\
\hline \multicolumn{4}{|l|}{ VAS score } \\
\hline Preoperative & $5.0 \pm 2.2$ & $4.2 \pm 1.9$ & 0.148 \\
\hline Final & $1.6 \pm 1.1$ & $1.7 \pm 1.4$ & 0.722 \\
\hline \multicolumn{4}{|l|}{ NDI score } \\
\hline Preoperative & $17.3 \pm 9.5$ & $18.7 \pm 6.9$ & 0.495 \\
\hline Final & $10.9 \pm 5.6$ & $11.9 \pm 5.1$ & 0.432 \\
\hline Blood loss (ml) & $313.8 \pm 88.4$ & $387.5 \pm 127.8$ & 0.011 \\
\hline Operating time (min) & $126.3 \pm 27.1$ & $145.4 \pm 38.6$ & 0.028 \\
\hline Length of stay (days) & $5.8 \pm 1.3$ & $7.1 \pm 1.5$ & $<0.001$ \\
\hline \multicolumn{4}{|l|}{ Complications (n) } \\
\hline Nerve root palsy & 1 & 8 & 0.018 \\
\hline Superficial wound infection & 2 & 3 & 1.000 \\
\hline CSF leakage & 1 & 2 & 1.000 \\
\hline Instrumentation failure & 0 & 0 & NA \\
\hline Reoperation & 0 & 0 & NA \\
\hline Cost (RMB) & $71.9 \pm 11.2$ & $78.6 \pm 9.4$ & 0.013 \\
\hline
\end{tabular}

JOA Japanese Orthopaedic Association; VAS visual analogue scale; NDI neck disability index; CSF cerebrospinal fluid; RMB Chinese Yuan; NA Not Applicable

treatment of patients with multilevel cervical myelopathy accompanying segmental instability. Our results suggest that LPSF was effective in maintaining the stability of the cervical spine with less sacrifice of mobility and surgical trauma for multilevel myelopathy with segmental instability compared to LCF.

Well maintained cervical alignment is needed for indirect spinal cord decompression. It is intuitive that loss of cervical lordosis is especially relevant to the LPSF group but not to the LCF group. This is manifested within the present study where the cervical lordosis was well maintained in the LCF group. Meanwhile, in the LPSF group there was a $31.1 \%$ decreased of cervical lordosis and 5 patients developed straight alignment at the final follow-up. This result is similar to pervious reports of cervical lordosis loss after laminoplasty surgery alone [4]. Because all patients in this study have segmental instability, which predisposes a patient to loss of cervical lordosis that may progress to kyphosis, this result indicates that LPSF contribute to segments stabilization, and decreases cervical lordosis loss. Considering it is possible that LPSF may result in loss of lordosis and even progression to kyphosis, same as laminoplasty alone technique, LPSF should only be recommended for patients with a well-aligned cervical spine.
Restricted cervical motion after operation is one of the patient concerns before cervical spinal operations. Preserving cervical movement is an advantage of laminoplasty over laminectomy and fusion. With strong metal instrumentation, LCF is a powerful tool to correct mal-aligned cervical spines and maintain cervical lordosis, but much of the cervical spine mobility is scarified. There is also a reduction of cervical ROM after laminoplasty alone, assumed to be caused by spontaneous laminar fusion [18]. Therefore, it is meaningful to investigate the effect of additional selective fusion after laminoplasty and its effect on cervical ROM. In this study, we found both groups experienced a significant decrease in ROM, but the decrease was considerably less in the LPSF than in the LCF group. This result indicates that LPSF provides the benefit of preserving physiological cervical motion.

Preoperative cervical kyphosis is not suitable for cervical laminoplasty and loss of cervical lordosis is correlated with delayed neurological function deterioration [19]. In this study, although LPSF was less powerful than LCF in preventing loss of cervical lordosis, this effect did not result in inferior neurological recovery. We found that both LPSF and LCF significantly improved the JOA score and no significant difference was detected in the recovery rates between the 2 groups. These results were similar to previous reports on the comparison between lanimoplasty and LCF [20].

Axial symptoms, including neck and shoulder pain and shoulder muscle spasm, occur frequently in patients with cervical spondylosis and have a significant negative impact on quality of life [21]. The axial symptoms are generally considered to originate from degenerated intervertebral discs or facet joints and are reported to worsen or newly emerge after laminoplasty [22]. Segmental instability is a significant risk factor for neck pain after laminoplasty [23, 24] and postoperative cervical ROM restriction could alleviate segmental instability and concomitant axial symptoms [24, 25]. In this study, both LPSF and LCF patients showed significant improvement in VAS and NDI scores at the final follow-up and the improvement between the 2 groups was similar. These findings indicate that selective fusion is effective for relieving axial symptoms after laminoplasty due to stabilization at the unstable segments and/or the restriction of cervical ROM after LPSF.

Extensive posterior structure resection and instrumentation will increase surgical time, blood loss and medical expenditure. As shown in this study, LPSF resulted in less surgical time and blood loss, indicating a relatively less invasive technique. Because implant costs are a big part of medical expenditure for patients in China, LPSF was more cost effective than LCF. We noticed shorten hospital stays may have also decreased the expenditure of patients who underwent LPSF surgery. 
Due to the low incidence of complications of both technologies, a large sample size is needed to detect the difference of complications. Therefore, a limitation of this study is the relatively small simple size. LPSF preserved the lamina, which may restrict excessive spinal cord posterior drift at the level of $\mathrm{C} 5$ and decreased mechanical tethering of C5 nerve root [26]. However, due to the limited sample size of the current study, it was not enough to support a lower incidence of C5 nerve root palsies in the LPSF group. The incidence of surgical complications were low in both groups, including wound infection, instrumentation failure, and CSF leakage. This study did not provided enough power to support significant difference of incidence of these complications either. Larger sample size research is needed in the further study.

There are other limitations to consider in the present study. We acknowledge the grouping was not prospectively randomized and controlled. Nearly all the LCFs were performed in the first two years, and LPSFs in the last four years of the study period. This variation was based on new techniques for less invasive and effective treatment of patients, but could have introduced bias. However, the demographic and baseline outcomes between the 2 groups were similar. We believe that the well-matched grouping was the major strength of this study. Furthermore, the follow-up time for both groups are limited. A follow-up of a few years (5 years or more) would be more adequate to see the longer term complications of LPSF and LCF. Considering the limitation of the current study, the efficiency of LPSF needs to be determined by further long-term clinical observation.

\section{Conclusions}

In conclusion, this 2-year clinical study suggest that LPSF produces comparable clinical outcomes with LCF surgery in the treatment of patients with OPLL accompanied by segmental instability. LPSF was found to be superior to LCF in preserving cervical ROM and decreasing surgical trauma and medical cost.

\section{Abbreviations \\ CSF: Cerebrospinal fluid; CT: Computer tomography; JOA: Japanese orthopaedic association; LCF: Laminectomy with fusion; LCL: Loss of cervical Iordosis; LPSF: Laminoplasty with selective fixation; MRI: Magnetic resonance imaging; NDI: Neck disability index; OPLL: Ossification of the posterior longitudinal ligament; ROM: Range of motion; VAS: Visual analogure scale}

\section{Acknowledgements}

We would like to thank Editage (www.editage.cn) for English language editing.

\section{Authors' contributions}

JZ performed all the surgery, and designed this study. CQZ are the main assistants in operation, and were major contributor in data collection. HJT and KZ contributed to design of the study, obtained ethical permission, performed data analysis, interpretation of results. LD and YZG wrote the main manuscript text and TJZ prepared the figures. All authors reviewed the manuscript and approved the final manuscript.

\section{Funding}

This study was partly supported by the National Natural Science Foundation of China (grant no. 81071503, 81572168, 81871790); 2016 Henan Science and Technology Research Project (162102310018); 2018 National and Provincial Co-Construction Project of Henan Provincial Medical Science and Technology Research (SBGJ2018076) and Henan Provincial Zhongyuan Thousand Talents Plan(ZYQR201912122)

\section{Availability of data and materials}

The datasets used and/or analysed during the current study are available from the corresponding author on reasonable request.

\section{Declarations}

Ethics approval and consent to participate

This research involving human data have been performed in accordance with the Declaration of Helsinki and have been approved by The Ethics Committee of Clinical Medicine Research, Shanghai Ninth People's Hospital. Because of its retrospective design, and all of the clinical and radiological data were collected and analysed anonymously, the Ethics Committee of Clinical Medicine Research, Shanghai Ninth People's Hospital waived this study from obtaining informed consent for patients.

\section{Consent for publication}

Written, informed consent was obtained for participants, for the publication of identifying images or other personal or clinical details of participants that compromise anonymity.

\section{Competing interests}

The authors declare that they have non-financial competing interests.

\section{Author details}

'Department of Spine Surgery, Henan Provincial People's Hospital, People's Hospital of Zhengzhou University, 7 Weiwu Road, 450000 Zhengzhou, Henan, People's Republic of China. ${ }^{2}$ Shanghai Key Laboratory of Orthopedic Implants, Department of Orthopedics, Shanghai Ninth People's Hospital, Shanghai Jiao Tong University School of Medicine, 639 Zhizaoju Road, 200011 Shanghai, People's Republic of China.

Received: 13 January 2021 Accepted: 16 April 2021

Published online: 07 May 2021

\section{References}

1. Iwasaki K, Furukawa Kl, Tanno M, et al. Uni-axial cyclic stretch induces Cbfa1 expression in spinal ligament cells derived from the patients with ossification of the posterior longitudinal ligament. Calcif Tissue Int. 2004;74: 448-57.

2. Azuma Y, Kato $Y$, Taguchi T. Etiology of cervical myelopathy induced by ossification of the posterior longitudinal ligament: determining the responsible level of OPLL myelopathy by correlating static compression and dynamic factors. J Spinal Disord Tech. 2010;23:166-169.

3. van Geest S, de Vormer AM, Arts MP, et al. Long-term follow-up of clinical and radiological outcome after cervical laminectomy. Eur Spine J. 2015;24: S229-S235.

4. Cao J, Zhang J, Yang D, et al. Multivariate analysis of factors associated with kyphotic deformity after laminoplasty in cervical spondylotic myelopathy patients without preoperative kyphotic alignment. Sci Rep. 2017;7: 43443.

5. Tang JA, Scheer JK, Smith JS, et al. The impact of standing regional cervical sagittal alignment on outcomes in posterior cervical fusion surgery. Neurosurgery. 2015;76: S14-S21.

6. Yonenobu K, Hosono N, Iwasaki M, et al. Neurologic complications of surgery for cervical compression myelopathy. Spine (Phila Pa 1976). 1991;16: 1277-1282.

7. Dai L, Ni B, Yuan W, et al. Radiculopathy after laminectomy for cervical compression myelopathy. J Bone Joint Surg Br. 1998;80:846-849.

8. Chen Y, Wang X, Chen D, et al. Posterior Hybrid Technique for Ossification of the Posterior Longitudinal Ligament Associated With Segmental Instability in the Cervical Spine. J Spinal Disord Tech. 2014;27:240-244. 
9. Chen $Y$, Chen D, Wang $X$, et al. Significance of segmental instability in cervical ossification of the posterior longitudinal ligament and treated by a posterior hybrid technique. Arch Orthop Trauma Surg. 2013;133:171-177.

10. Vernon H, Mior S. The Neck Disability Index: a study of reliability and validity. J Manipulative Physiol Ther. 1991;14(7):409-415.

11. Kim TH, Lee SY, Kim YC, et al. T1 slope as a predictor of kyphotic alignment change after laminoplasty in patients with cervical myelopathy. Spine (Phila Pa 1976). 2013;38: E992-E997.

12. Zhang JT, Li JQ, Niu RJ, et al. Predictors of cervical lordosis loss after laminoplasty in patients with cervical spondylotic myelopathy. Eur Spine J. 2017:26:1205-1210.

13. Chang H, Kim C, Choi BW. Selective laminectomy for cervical spondylotic myelopathy a comparative analysis with laminoplasty technique. Arch Orthop Trauma Surg. 2017;137: 611-616.

14. Su N, Fei Q, Wang BQ, et al. long-term outcomes and prognostic analysis of modifed open-door laminoplasty with lateral mass screw fusion in treatment of cervical spondylotic myelopathy. Ther Clin Risk Manag. 2016; 12:1329-1337.

15. Edwards CC, Heller JG, Hal Silcox D. T-saw laminoplasty for the management of cervical spondylotic myelopathy: clinical and radiographic outcome. Spine. 2000;25:1788-1794.

16. Hirabayashi K, Toyama Y, Chiba K. Expansive laminoplasty for myelopathy in ossification of the longitudinal ligament. Clin Orthop Relat Res. 1999;359:3548.

17. Wada E, Suzuki S, Kanazawa A, et al. Subtotal corpectomy versus laminoplasty for multilevel cervical spondylotic myelopathy: a long-term follow-up study over 10 years. Spine. 2001;26:1443 - 447; discussion 1448.

18. Hyun SJ, Rhim SC, Roh SW, et al. The Time Course of Range of Motion Loss After Cervical Laminoplasty: A Prospective Study With Minimum Two-Year Follow-up. Spine (Phila Pa 1976). 2009;34(11):1134-1139

19. Du W, Wang L, Shen Y, et al. Long-term impacts of different posterior operations on curvature, neurological recovery and axial symptoms for multilevel cervical degenerative myelopathy. Eur Spine J. 2013;22(7):15941602.

20. Blizzard DJ, Caputo AM, Sheets CZ, et al. Laminoplasty versus laminectomy with fusion for the treatment of spondylotic cervical myelopathy: short-term follow-up. Eur Spine J. 2017:26(1):85-93.

21. Kimura $A$, Endo $T$, Inoue $H$, et al. Impact of axial neck pain on quality of life after laminoplasty. Spine (Phila Pa 1976). 2015;40(24): E1292-E1298.

22. Wang M, Luo XJ, Deng QX, et al. Prevalence of axial symptoms after posterior cervical decompression: a meta-analysis. Eur Spine J. 2016;25(7): 2302-2310.

23. Oichi T. Cervical anterolisthesis: A predictor of poor neurological outcomes in cervical spondylotic myelopathy patients after cervical laminoplasty. Spine (Phila Pa 1976). 2016;41(8): E467-E473.

24. Kimura A, Shiraishi $Y$, Inoue $H$, et al. Predictors of Persistent Axial Neck Pain After Cervical Laminoplasty. Spine (Phila Pa 1976). 2018;43(1):10-15.

25. Nakashima H, Kato F, Yukawa Y, et al. Comparative effectiveness of opendoor laminoplasty versus French-door laminoplasty in cervical compressive myelopathy. Spine (Phila Pa 1976). 2014;39(8): 642-647.

26. Sodeyama T, Goto S, Mochizuki M, et al. Effect of decompression enlargement laminoplasty for posterior shifting of the spinal cord. Spine (Phila Pa 1976). 1999;24(15):1527-1531.

\section{Publisher's Note}

Springer Nature remains neutral with regard to jurisdictional claims in published maps and institutional affiliations.

Ready to submit your research? Choose BMC and benefit from:
- fast, convenient online submission
- thorough peer review by experienced researchers in your field
- rapid publication on acceptance
- support for research data, including large and complex data types
- gold Open Access which fosters wider collaboration and increased citations
- maximum visibility for your research: over 100M website views per year
At BMC, research is always in progress.
Learn more biomedcentral.com/submissions

